\title{
Surface Roughness Optimization of AL 7075 Aluminum Alloy in Hole Turning Process
}

\author{
Ömer SEÇGI'N ${ }^{1}$ \\ Department of Mechanical \\ Engineering Piri Reis University \\ Istanbul, Turkey \\ Email: osecgin@gmail.com
}

\begin{abstract}
One of the main purposes of machining is to minimize the surface roughness of the workpiece. In this study, the hole turning operation was applied to AL7075 alloy. First, the parts were drilled on a CNC lathe with an HSS drill. Then the holes were turned. The effects of turning parameters on surface roughness were determined by Signal/Noise analysis. As a result of the study, it has been determined that the most important parameter for surface roughness is the cutting speed. It has also been found that the use of a small amount of cutting depth gives a better surface roughness.
\end{abstract}

Keywords- AL7075, S/N analysis, Taguchi, turning

\section{INTRODUCTION}

Aluminum alloys are widely used in areas such as space, computers, and health. Due to this widespread use, the machinability of aluminum alloys has been an important research topic [1].

Reducing the surface roughness of the machined parts is very important in machining. For this reason, many studies have been done on average surface roughness (Ra). It is desired that the average surface roughness is at a minimum level. The low surface roughness of the material increases the mechanical properties of the material [2].

Raykar at all made parameter optimization in the external turning operation of AL 7075 material. They used both the S/N analysis method and the Methodology of Gray Relational Analysis [3]. Marko at all investigated the parameter optimization of the $\mathrm{C} 45 \mathrm{E}$ material in the turning process using the Swarm Optimization method [4]. Martín-Béjar at all investigated the effect of cutting speed and feedrate parameters on surface microhardness when turning AL 7075 material. Özerkan investigated the effect of surface roughness on material fatigue by turning Al 6061-T913 material's outer diameter. In his study, he determined three different parameters [5]. These are: cutting speed, feed and cutting depth. In this study, these parameters were used.

When the literature is examined, it is understood that the studies related to turning focused on external turning. There is not enough work on hole turning. In this study, the turning operation of AL 7075 aluminum alloy has been investigated. Optimum levels of parameters were determined by signal/noise analysis. The optimum cutting parameters, which give the smallest surface roughness, have been determined.

\section{MATERIALS AND METHOD}

In this study, the AL 7075 alloy's surface roughness was investigated in the hole turning operation. First of all, the part was drilled with an $11 \mathrm{~mm}$ diameter HSS drill. Later, it was turned using a boring bar with TEKNIK branded "S06 08H SCLCR 06". Later, it was turned using a boring bar with TEKNIK branded "S06 08H SCLCR 06". CCMT 060202 inserts used for the cutting tool. Tool holder and cutting insert were given in Fig. 1.

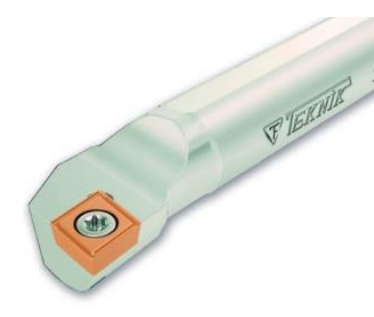

A

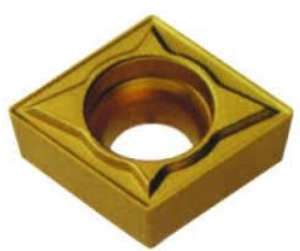

B
Fig. 1. Cutting tools. A) Tool holder; B) Cutting insert.

Three different test parameters were determined. These are cutting speed $(\mathrm{Vc})$, feed rate (f) and cutting depth (Ap). Three different levels were determined for each parameter. In Table 1 cutting parameters and levels were given.

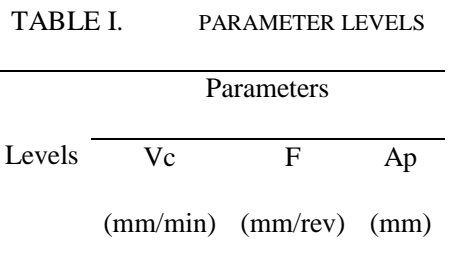

$\begin{array}{llll}1 & 50 & 0.02 & 0.1\end{array}$




\begin{tabular}{lccc}
2 & 75 & 0.04 & 0.2 \\
3 & 100 & 0.06 & 0.3 \\
\hline
\end{tabular}

While creating the experiment set, the Taguchi L9 orthogonal array was used. After the experiments were completed, the average surface roughness $(\mathrm{Ra})$ of the pieces was measured. Later, Signal/Noise $(\mathrm{S} / \mathrm{N})$ analysis was performed and optimum parameter levels were determined. In Signal/Noise analysis, the "smaller is better" equation was used [6]. Minitab L18 program was used in the analysis.

\section{RESULTS}

The experimental set and responses are given in Table II. The table was divided into three different column groups. Experiment numbers are given in the first column. In the second part, experimental parameters were given. In the last part, responses ( $\mathrm{Ra}$ and $\mathrm{S} / \mathrm{N}$ ratios) were given.

TABLE II. EXPERIMENTAL PARAMETERS AND RESPONSES

\begin{tabular}{|c|ccc|cc|}
\hline \multirow{2}{*}{$\begin{array}{c}\text { Experiment } \\
\text { No }\end{array}$} & \multicolumn{3}{|c|}{ Parameters } & \multicolumn{2}{c|}{ Responses } \\
\cline { 2 - 6 } & Vc & f & Ap & Ra & SNRA1 \\
\hline $\mathbf{1}$ & 50 & 0.02 & 0.1 & 0.292 & 10.692 \\
$\mathbf{3}$ & 50 & 0.04 & 0.2 & 0.507 & 5.900 \\
$\mathbf{4}$ & 75 & 0.02 & 0.2 & 1.919 & -5.661 \\
$\mathbf{5}$ & 75 & 0.04 & 0.3 & 1.680 & -4.506 \\
$\mathbf{6}$ & 75 & 0.06 & 0.1 & 0.593 & 4.539 \\
$\mathbf{7}$ & 100 & 0.02 & 0.3 & 0.512 & 5.815 \\
$\mathbf{8}$ & 100 & 0.04 & 0.1 & 0.443 & 7.072 \\
$\mathbf{9}$ & 100 & 0.06 & 0.2 & 0.125 & 18.062 \\
\hline
\end{tabular}

According to Table II, the largest $\mathrm{S} / \mathrm{N}$ ratio (the smallest surface roughness) was obtained in experiment number 9 . In this experiment, $100 \mathrm{~mm} / \mathrm{min}$ cutting speed, $0.06 \mathrm{~mm} / \mathrm{rev}$ feedrate and $0.2 \mathrm{~mm}$ cutting depth used.

The main effect plot for means was given in Fig 2. As the progress value increases according to the graph, the surface roughness decreases. When the depth of cut decreases, the surface roughness also decreases. According to this graph, the best surface roughness is obtained at the following levels: $100 \mathrm{~mm} / \mathrm{min}(\mathrm{Vc}), 0.06$ $\mathrm{mm} / \mathrm{rev}$ (f) and $0.1 \mathrm{~mm}(\mathrm{ap})$.

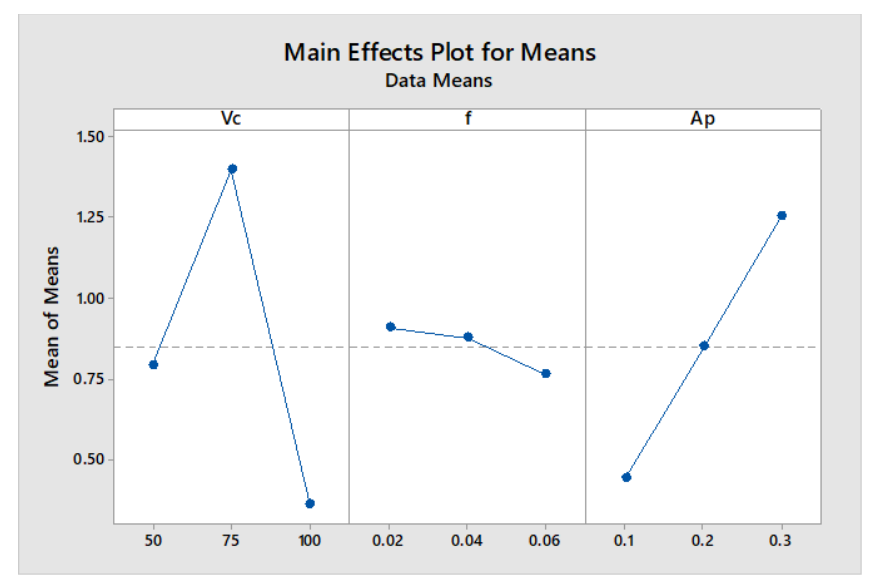

Fig. 2. Main effect plot for means.

The response table for the Signal/Noise ratios was given in Table III. According to the table, the factor that most affects the average surface roughness is the cutting speed ( Vc).

\section{TABLE III. RESPONSE TABLE FOR S/N RATIOS}

\begin{tabular}{lrrr}
\hline Level & Vc & f & Ap \\
\hline $\mathbf{1}$ & 4.2210 & 3.6151 & 7.4344 \\
$\mathbf{2}$ & -1.8763 & 2.8219 & 6.1000 \\
$\mathbf{3}$ & 10.3161 & 6.2239 & -0.8735 \\
Delta & 12.1924 & 3.4020 & 8.3079 \\
Rank & 1 & 3 & 2 \\
\hline
\end{tabular}

The main effect plot for the signal to noise ratios was given in Fig. 3. The level that gives the highest $\mathrm{S} / \mathrm{N}$ ratio of each parameter is the optimum level [7], [8]. Optimum levels for average surface roughness according to the graph: $100 \mathrm{~mm} / \mathrm{min}(\mathrm{Vc}), 0.06 \mathrm{~mm} / \mathrm{rev}$ (f) and $0.1 \mathrm{~mm}$ (ap).

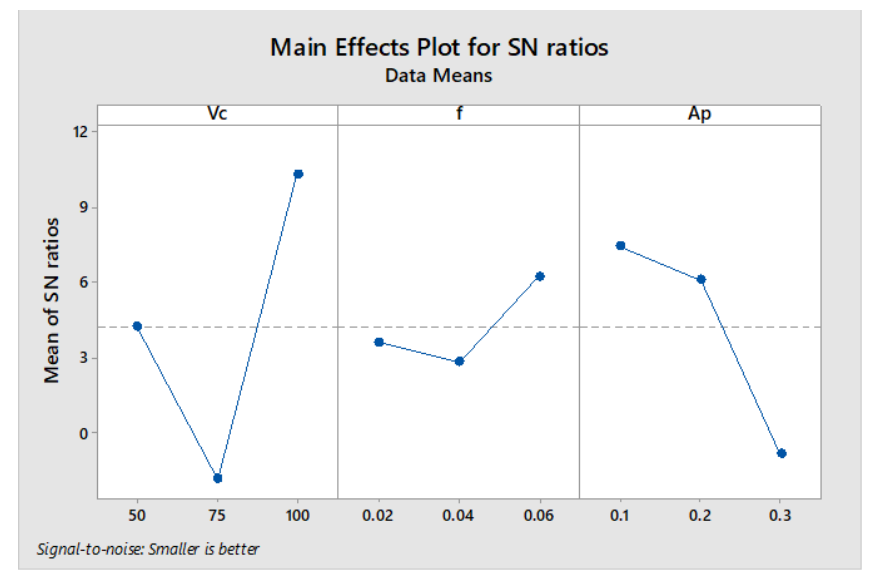


Fig. 3. Main effect plot for $\mathrm{S} / \mathrm{N}$ ratios.

The contour plot of Ra vs Vc;f was given in Fig. 4. Contour plot of Ra vs Vc;Ap was given in Fig. 5. Contour plot of Ra vs f;Ap was given in Fig. 6. According to these graphics, it appears that the small values of feedrate give smaller surface roughness. This situation is compatible with the literature [9]. It is understood that large values give smaller surface roughness in cutting depth. The middle values ( $75 \mathrm{~mm} / \mathrm{min}$ ) of the cutting speed give a worse surface roughness. In general, it is seen that high cutting speed gives a better surface roughness. This is similar to the external turning process, consistent with the literature [10], [11].

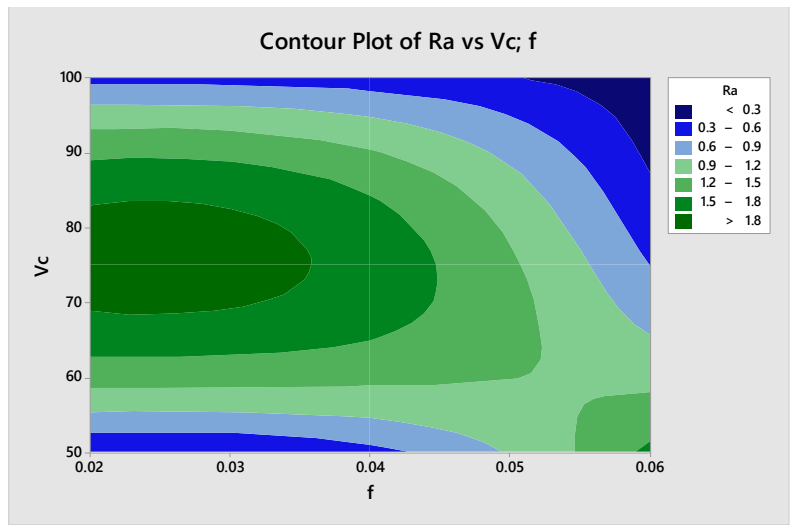

Fig. 4. Contour plot of Ra vs Vc;f.

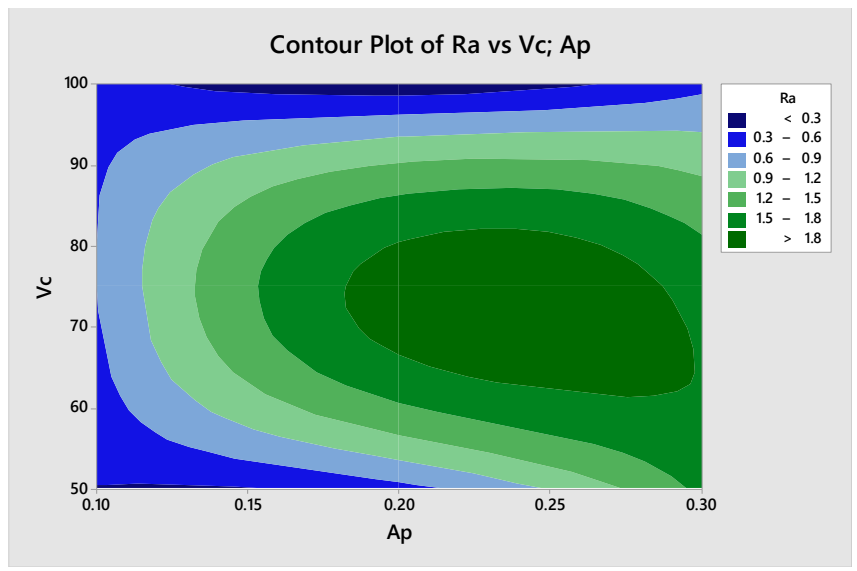

Fig. 5. Contour plot of Ra vs Vc;Ap.

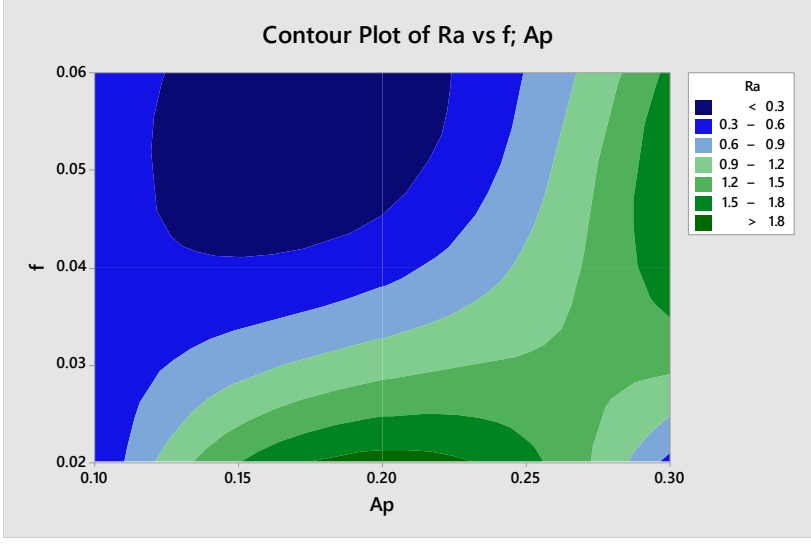

Fig. 6. Contour plot of Ra vs f;Ap.

\section{Conclusions}

In this study, the hole turning process was applied to AL7075 material which is frequently used in the aviation and defense industry. The aforementioned material was first drilled with an HSS drill on a CNC lathe and then turned inside the hole. The effects of internal turning parameters on surface roughness were determined by $\mathrm{S} / \mathrm{N}$ analysis. As a result of the study, the following information was obtained:

- If the feedrate value is high, smaller surface roughness is obtained.

- If the depth of cut is reduced, the surface roughness also decreases.

- Optimum levels for surface roughness:

○ For cutting speed (Vc) $100 \mathrm{~mm} / \mathrm{min}$,

○ For feedrate (f) $0.06 \mathrm{~mm} / \mathrm{rev}$

○ For cutting depth (ap) $0.1 \mathrm{~mm}$

\section{REFERENCES}

[1] Sevim and O. Genc, "Investigation of Vibrations For Al-7075 Material's Milling Machine For Different Turning And Feeding Speeds Of Drilling Process," INTERNATIONAL JOURNAL OF SCIENTIFIC \& TECHNOLOGY RESEARCH, vol. 4, no. 04, pp. 50-57, 2015.

[2] H. Yaka, L. Uğur, and H. Akkuş, "Investigation of Surface Roughness with Multiple Regression in Turning of AISI 1040 Steel," Afyon Kocatepe Üniversitesi Fen ve Mühendislik Bilimleri Dergisi, vol. 16, pp. 770-775, 2016, doi: 10.5578/fmbd.34280.

[3] S. J. Raykar, D. M. D. Addona, and A. M. Mane, "Multi-objective optimization of high speed turning of Al 7075 using grey relational analysis," Procedia CIRP, vol. 33, pp. 293-298, 2015, doi: 10.1016/j.procir.2015.06.052.

[4] H. Marko, K. Simon, I. Tomaz, P. Matej, B. Joze, and B. Miran, "Turning Parameters Optimization using Particle Swarm Optimization," Procedia Engineering, vol. 69, pp. 670-677, 2014, doi: 10.1016/j.proeng.2014.03.041. 
[5] H. B. Özerkan, "Theoretical Evaluation of the Surface Roughness Effect on the Fatigue Life in Turning," Çukurova University Journal of the Faculty of Engineering and Architecture, vol. 33, no. June, pp. 189-198, 2018.

[6] C. Materials, O. Mart, A. R. Motorcu, and O. Mart, "Evaluation of surface roughness and material removal rate in the wire electrical discharge machining of Al / B4C composites via the Taguchi method," Journal of Composite Materials, vol. 50, no. 18, pp. 2575-2586, 2016, doi: 10.1177/0021998315609788.

[7] G. Meral, M. Sar, M. Mia, H. Dilipak, and Ş. Ulvi, "Optimization of hole quality produced by novel drill geometries using the Taguchi S/N approach," International Journal of Advanced Manufacturing Technology, pp. 339-355, 2019.

[8] M. Vijay Kumar, B. J. Kiran Kumar, and N. Rudresha, "Optimization of Machining Parameters in CNC Turning of Stainless Steel (EN19) by TAGUCHI'S Orthogonal Array Experiments," Materials Today: Proceedings, vol. 5, no. 5, pp. 11395-11407, 2018, doi: 10.1016/j.matpr.2018.02.107.

[9] D. Das, V. Chakraborty, B. Kumar Nanda, and B. Chandra Routara, "Turning performance of Al 7075/SiCp MMC and multi-response optimization using WPCA and Taguchi approach," Materials Today: Proceedings, vol. 5, no. 2, pp. 6030-6037, 2018, doi: 10.1016/j.matpr.2017.12.207.

[10] J. P. Ajithkumar and A. M. Xavior, "Cutting Force and Surface Roughness Analysis During Turning of Al 7075 Based Hybrid Composites," Procedia Manufacturing, vol. 30, pp. 180-187, 2019, doi: 10.1016/j.promfg.2019.02.026.

[11] P. R. C. R, M. S. Bhagyashekar, and Narendraviswanath, "Effect of Machining Parameters on the Surface Roughness while Turning Particulate Composites," Procedia Engineering, vol. 97, pp. 421-431, 2014, doi: 10.1016/j.proeng.2014.12.266. 